\title{
Embrace the Future of Drug Therapy of Diabetes Mellitus: Five Novel Approaches with Remarkable Potentials
}

\author{
Mina T Kelleni ${ }^{1,2 *}$ \\ ${ }^{1}$ Department of Pharmacology, College of Medicine, Jouf University, Kingdom of Saudi Arabia \\ ${ }^{2}$ Department of Pharmacology, Faculty of medicine, Minia Univesity, Egypt
}

Received: 眥 December 21, 2018; Published: 阱January 16, 2019

*Corresponding author: Mina T Kelleni, Department of Pharmacology, College of Medicine, Jouf University, Kingdom of Saudi Arabia

\section{Opinion}

Every year millions of patients are diagnosed with diabetes mellitus and millions die because of its complications. Unfortunately, the numbers are remarkably escalating, and the current pharmacotherapy isn't satisfactory not only to a substantial number of patients but also to clinicians as well. Five current and potential innovative approaches aiming at finding an ideal cure of diabetes mellitus are discussed in this article aiming to promote, encourage and support the researchers performing them. As a clinician as well as a pharmacologist, I find myself as well as most of my colleagues belonging to different continents on earth are not satisfied with the current remedies used to manage diabetes. Indeed several groups of drugs like dipeptidyl peptidase 4 inhibitors and sodium glucose cotransporter-2 inhibitors have been developed in the last decade and markedly improved control of diabetes, yet the search for ideal anti-diabetic agent having a perfect control over diabetes, no contraindications and negligible adverse effects or long term safety concerns still has a long path to reach its goal.

The search for the ideal anti-diabetic drugs is undergoing in two main directions; the first modifies existing therapies either through unprecedented drug combinations, modified drug molecules, or improved delivery systems and its aim is to nullify some of the undesirable side effects of traditional therapies as well as to enhance effectiveness and the other aims at exploring newer drug targets e.g. protein kinase B (Akt/PKB), AMP-activated protein kinase, sirtuin or utilize advanced techniques e.g. end barrier, gene therapy and stem cell technology wishing to develop new drugs/modalities to manage diabetes [1]. One of the promising future potential approaches is the transcription factor hepatocyte nuclear factor-1 alpha (HNF-1A) which is involved in normal pancreas development and function and some of its common variants confer type 2 diabetes risk. Recently, overexpression of protein inhibitor of activated STAT (PIAS gamma) was shown to repress the transcriptional activity of HNF-1A as well as to cause the translocation of HNF-1A to the nuclear periphery. Further, E3 SUMO ligase PIAS gamma was also shown to regulate HNF1A SUMOylation with functional implications, representing new targets for drug development and precision medicine in diabetes [2].

Another future potential approach focuses on the fact that amyloid polypeptide aggregates are causing direct islet beta cells toxicity impairing their function as well as decreasing their mass in the pancreas of type 2 diabetes patients. Amyloid deposits were also shown to be associated with several neurological disorders like Alzheimer's disease as well as to cancer and amyloid antagonists, some of them are natural, with huge potentials were encouraged to be researched, developed and experimented $[3,4]$. A third approach focuses on glucokinase; a glucose sensor in hepatocytes and islet beta cells promoting both glucose metabolism as well as glucosestimulated insulin secretion. Glucokinase activators have been reported as one kind of new potential drugs for treatment of type 2 diabetes and an experimental glucokinase activator has normalized oral glucose tolerance test and down-regulated blood lipid level, accelerated the ratio of beta cell/alpha cell mass, and alleviated the fatty liver of $\operatorname{KKA}(\mathrm{y})$ mice [5]. A fourth approach focuses on autophagy; a critical regulator of cellular homeostasis, autophagy deficiency in $\beta$-cells was shown to be a precipitating factor in the progression from obesity to diabetes due to inappropriate response to obesity-induced endoplasmic reticulum stress. 
An experimental autophagy enhancer was recently shown to improve the glucose profile not only of ob/ob mice but also of mice with diet-induced obesity and was suggested to be a new drug candidate for diabetes or metabolic syndrome with lipid overload $[6,7]$. The fifth approach focuses on augmentation of beta cell proliferation aiming at reversing diabetes. A molecular mechanism targets cyclin-dependent kinases (CDKs) and cyclins as their failure to access the nucleus is known to be responsible for quiescence or senescence in human and rodent beta cells. Further, there are several intrinsic factors that trigger the proliferation of beta cells and polyphenols, exendin 4, histone deacetylase inhibitors, glucagon-like peptide 1, phenyl pyruvic acid glucoside, and several flavonoids were shown to reduce the early apoptosis of beta cells partly through antioxidant activity [8]. Finally, of course these are not all the current approaches aiming to find a cure for diabetes but from my point of view, they represent a very promising group with remarkable potentials deserving more attention, encouragement as well as financial support to keep up the good work.

\section{References}

1. Chellappan DK, Yap WS, Ahmad Suhaimi N, Gupta G, Dua K (2018) Current therapies and targets for type 2 diabetes mellitus. Panminerva Medica 60(3): 117-131.

\section{ISSN: 2574-1241}

DOI: 10.26717/BJSTR.2019.13.002361

Mina T Kelleni. Biomed J Sci \& Tech Res

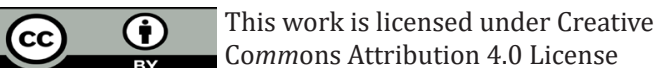

Submission Link: https://biomedres.us/submit-manuscript.php
2. Kaci A, Keindl M, Solheim MH, Njolstad PR, Bjorkhaug L, et al. (2018) The E3 SUMO ligase PIAS $\gamma$ is a novel interaction partner regulating the activity of diabetes associated hepatocyte nuclear factor-1 alpha? Scientific reports, p. 8.

3. Kelleni M (2016) Amyloid Antagonists: The Future of Type 2 Diabetes as well as Several Neurodegenerative Diseases Treatments. Diabetes and Obesity International Journal 1(1): 000106.

4. Kelleni M (2016) Amyloid Deposits: A Possible Link between Type 2 Diabetes Mellitus and Cancer. Diabetes and Obesity International Journal 1(6): 000131.

5. Lei L, Liu SN, Li YQ, Song H, He L, et al. (2018) The potential role of glucokinase activator SHP289-04 in anti-diabetes and hepatic protection. European Journal of Pharmacology 826: 17-23.

6. Lim H, Lim YM, Kim KH, Young Eui Jeon, Kihyoun Park, (2018) A novel autophagy enhancer as a therapeutic agent against metabolic syndrome and diabetes. Nature communications, p. 9.

7. Quan W, Lim YM, Lee MS (2012) Role of autophagy in diabetes and endoplasmic reticulum stress of pancreatic $\beta$-cells. Experimental \& molecular medicine 44(2): 81-88.

8. Sabir S, Saleem A, Akhtar MF, Saleem M, Raza M (2018) Increasing beta cell mass to treat diabetes mellitus. Advances in Clinical and Experimental Medicine 27(9): 1309-1315.

$\begin{array}{ll}\text { BIOMEDICAL } & \text { Assets of Publishing with us } \\ \text { RESEARCHES } & \text { - Global archiving of articles } \\ \text { - Immediate, unrestricted online access } & \text { - Rigorous Peer Review Process } \\ & \text { - Authors Retain Copyrights }\end{array}$

